\title{
Toward a phenomenological account of embodied subjectivity in autism
}

\section{Boldsen, Sofie}

Published in:

Culture, Medicine and Psychiatry

DOI:

10.1007/s11013-018-9590-y

Publication date:

2018

Document Version

Peer reviewed version

Citation for published version (APA):

Boldsen, S. (2018). Toward a phenomenological account of embodied subjectivity in autism. Culture, Medicine and Psychiatry, 42(4), 893-913. https://doi.org/10.1007/s11013-018-9590-y

\section{General rights}

Copyright and moral rights for the publications made accessible in the public portal are retained by the authors and/or other copyright owners and it is a condition of accessing publications that users recognise and abide by the legal requirements associated with these rights.

- Users may download and print one copy of any publication from the public portal for the purpose of private study or research.

- You may not further distribute the material or use it for any profit-making activity or commercial gain.

- You may freely distribute the URL identifying the publication in the public portal.

Take down policy

If you believe that this document breaches copyright please contact rucforsk@kb.dk providing details, and we will remove access to the work immediately and investigate your claim. 


\title{
Toward a Phenomenological Account of Embodied Subjectivity in Autism
}

\author{
Sofie Boldsen ${ }^{1}$
}

(C) Springer Science+Business Media, LLC, part of Springer Nature 2018

\begin{abstract}
Sensorimotor research is currently challenging the dominant understanding of autism as a deficit in the cognitive ability to 'mindread'. This marks an emerging shift in autism research from a focus on the structure and processes of the mind to a focus on autistic behavior as grounded in the body. Contemporary researchers in sensorimotor differences in autism call for a reconciliation between the scientific understanding of autism and the first-person experience of autistic individuals. I argue that fulfilling this ambition requires a phenomenological understanding of the body as it presents itself in ordinary experience, namely as the subject of experience rather than a physical object. On this basis, I investigate how the phenomenology of Maurice Merleau-Ponty can be employed as a frame of understanding for bodily experience in autism. Through a phenomenological analysis of Tito Mukhopadhyay's autobiographical work, How can I talk if my lips don't move (2009), I illustrate the relevance and potential of phenomenological philosophy in autism research, arguing that this approach enables a deeper understanding of bodily and subjective experiences related to autism.
\end{abstract}

Keywords Autism · Phenomenology · Embodied subjectivity · Movement · Perception · Self-experience

\section{Introduction}

'Theory of mind' and its equivalents 'mindreading' and 'mentalizing' have since the 1980's played a leading role in discussions of social understanding in psychology and philosophy of mind, and has rightly earned the label 'paradigm' in autism

Sofie Boldsen

boldsen@ruc.dk

1 Department of Psychology, Roskilde University, Universitetsvej 1, 4000 Roskilde, Denmark 
research. When Simon Baron-Cohen, Alan Leslie and Uta Frith (1985) proposed the idea that autistic children lack the ability to 'mindread,' autism became established as a disorder of the higher-order cognitive abilities. In recent years, this picture has changed as cognitive scientists recognize that cognition must be understood in its dynamic relation to bodily movement, perceptual processes and social interaction (Glenberg, Witt, and Metcalfe 2013). In the context of autism research, this shift in view is represented in a growing body of research investigating how sensorimotor differences might underlie what we know as autistic behavior (Leary and Hill 1996; Brincker and Torres 2013; De Jaegher 2013; Donnellan, Hill, and Leary 2012; Robledo, Donnellan, and Strandt-Conroy 2012; Whyatt and Craig 2013). The 'sensorimotor perspective' on autism is a diverse movement gathering various disciplines such as neuroscience, developmental psychology, action-perception research, and philosophy, in order to reconceptualize autism in terms of movement and sensation.

By drawing on previous work that explores the philosophy of Merleau-Ponty indepth as a conceptual frame in autism research (Boldsen 2016), this article discusses how phenomenology enables an understanding of the experiential dimension of sensorimotor differences in autism. The analyses and discussions in this article will therefore be relevant to several audiences, including autism researchers interested in the lived experiences of autistic individuals and philosophers interested in the application of phenomenology.

\section{Exploring Autistic Embodiment and Experience}

Autistic individuals have long been known to move in ways that are at times puzzling and seemingly meaningless: endless rocking back and forth, flicking of fingers, odd hand postures, repeatedly touching certain objects, stimming or unusual gait and body posture. In their groundbreaking article, Martha Leary and David Hill (1996) point out how autistic behavior is usually interpreted as a lack of interest in participating in social or communicative activities and suggest that autistic behaviors should be understood in light of sensorimotor differences. The concept of behavior involved in this research emphasizes how our actions and interactions are made possible by our ability to sense our own movements and regulate the motions of our body in line with this sensory feedback. In this way, behavior is highly dependent upon the interaction between sensory and motor systems, which may be different in autism (Donnellan, Hill, and Leary 2012). Most authors investigating sensorimotor differences in autism suggest methods of objectively measuring and quantifying the interaction between neurological processes, sensory systems and microscopic movement:

Movement is measurable. Its quantification can bring the science of autism to a higher, more rigorous standard that is lacking today. [...] We would at last be able to follow the true scientific method, and avoid jeopardizing the future of ASD kids and adults with mere guesses and non-scientific controversies that have not been supported by rigorous research. (Torres and Donnellan 2015:1-2) 
The ambition is to avoid reliance on observation of autistic behaviors, which may too easily invite misinterpretations of these behaviors as expressions of social impairment (Leary and Hill 1996). Taken together, the various approaches to sensorimotor problems in autism represent a view that strongly objects to the dominant and cognitively driven explanations of autism ${ }^{1}$ (Brincker and Torres 2013; Whyatt and Craig 2013).

Elizabeth Torres and Anne Donnellan (2015) argue that autism research should include and accommodate the experiences and perspectives of autistic individuals. This view reflects a growing interest in the narratives and experiences of people diagnosed with autism that began to flourish around the 1990's (Hacking 2009). Within some areas of autism research, scholars have begun to include autistics as an active part of the research process, for example through participatory research methods (Milton and Moon 2012; Pellicano, Dinsmore, and Charman 2013). Furthermore, a number of autistic individuals are themselves becoming autism researchers (Milton 2014a; Arnold 2012; Murray, Lesser, and Lawson 2005; Kapp 2013; Nolan and McBride 2015). The emergence of self-advocacy networks and the fact that autistic individuals are participating actively in the processes of knowledge production reflects an emerging shift in the distribution of power in autism research (Graby 2012; Milton, Mills, and Pellicano 2012). Authors within the area of sensorimotor research on autism aim to accommodate and embrace this development. As Jodi Robledo, Anne Donnellan and Karen Strandt-Conroy state:

If we wish to truly understand the experience of sensory and movement differences for individuals with autism, we must explore their experiences and perspectives. [...] [I]n studying autism we need to elicit information from one of the most valuable resources-people with the label of autism. (Robledo, Donnellan, and Strandt-Conroy 2012:1-2)

The emergence of the sensorimotor perspective on autism and growing interest in autistic experiences poses an important question: how does the subjective experience of autistic individuals relate to the measurable physiological motions arguably underlying natural behavior? This calls for a theoretical and methodological framework that bridges the gap between subjective experience and the physical processes of the body. One possible approach is to integrate relevant phenomenological analyses of embodied subjectivity. From a phenomenological perspective, the body is intrinsically connected with subjectivity and shapes the way we experience the world, each other, and ourselves. On this basis, I argue that phenomenology provides an adequate framework for addressing the experiential dimension of sensorimotor differences in autism. The philosophical tradition of phenomenology provides perspectives on themes that are deeply interesting to the field of psychology, such as subjectivity, intersubjectivity, affectivity, and embodiment. Even though phenomenology over the past 100 years has become a diverse field, a common trait between the different approaches is the attempt to uncover and examine how the world is experienced prior to conscious thought,

\footnotetext{
${ }^{1}$ E.g. the theory of mind deficit hypothesis, weak central coherence theory and executive functioning theory.
} 
conceptual knowledge and linguistic communication. In other words, phenomenology aims to describe a level of awareness of the world, oneself and others that is pre-reflective. Maurice Merleau-Ponty (2012), a classical proponent of phenomenology, famously states that the ways in which we encounter the world consciously, conceptually or scientifically presuppose and are shaped by immediate and prereflective bodily experience.

\section{Merleau-Ponty and Embodied Subjectivity}

Unlike his phenomenological predecessors, Merleau-Ponty made the body the center of his philosophy, and throughout his writing, he emphasized its constitutive role in subjective experience. Within a phenomenological framework, the experience of sensorimotor processes refers to a very basic form of self-awareness: a prereflective experience of oneself as a sensing and moving body that implicitly structures one's conscious and thematic experiences of the world. In MerleauPonty's phenomenology, this means that in any experience, we are always implicitly aware of ourselves as sensing and moving bodies, and ultimately, that the body is the subject of experience.

In his main philosophical work Phenomenology of Perception, Merleau-Ponty shows how experience and knowledge of the world does not originate in reflective consciousness, but rather in our bodily engagement with the world. This insight marks the way Merleau-Ponty (2012:139) extends and redefines the classical phenomenological notion of intentionality as being solidly grounded in the body. What renders the world meaningful in experience is not the way I can think about its objects or make judgments about them, neither is it the way my body as a bundle of physical processes is designed to sense it. Rather, the world presents itself as meaningful by virtue of my body's perceptual engagement in it. Merleau-Ponty understands perception to be a certain form of bodily being-in-the-world rather than a passive process, where the world is merely represented through the medium of the sensory system. For Merleau-Ponty, perception is an active process where the subject involves itself bodily in the world, and is thereby shaped by the movements of the body. Movement is not merely the changing of the body's position in space, but the unfolding of a perspective on the world. In movement, I recognize the world as a field of possible actions as I reach out and engage with the objects in my perceptual surroundings. Through movement, I actively join with the world, express my projects and my points of view.

Returning to the topic of autism and sensorimotor problems, some important differences emerge between a phenomenological approach and the perspective offered by sensorimotor research. In the framework of Merleau-Ponty's phenomenology, it would only provide one piece of the puzzle to measure and quantify movement and sensation. In order to fully understand sensorimotor problems, it is necessary to approach bodily issues as subjective in nature and understand how they shape and affect the individual's way of experiencing and engaging with the world. Within a phenomenological framework, the body cannot be understood as a purely 
physical system, and therefore, we must turn our attention to the body as the subject rather than the object of experience.

In recent years, a number of articles have emerged that use phenomenology as a methodological and theoretical framework for understanding autism (Huws and Jones 2015; Zukauskas, Silton, and Assumpção 2009; Williams 2004; Newman, Cashin, and Waters 2010; Zahavi and Parnas 2003). Furthermore, some articles and conference papers address different aspects of autism from the perspective of Merleau-Ponty's phenomenology (Zahavi 2005; He and Jespersen 2015; Dant 2015; Stawarska 2006; Rasmussen, unpub.; Kristensen 2012). These articles and manuscripts address highly relevant themes to autism research, such as learning, social cognition, play and communication. However, with the exception of Dan Zahavi's analysis of bodily self-awareness in autism, none of the authors tackle the experiential dimension of sensorimotor processes directly. Although Zahavi's work do engage with the empirical discipline of developmental psychology, his work remains theoretical in ambition. In this way, the aim of this article differs from that of Zahavi's in that the relevance of Merleau-Ponty's phenomenology is assessed by its potential of making sense of concrete experiences described by autistic individuals.

\section{Autistic Autobiography and the Case of Tito Rajarshi Mukhopadhyay}

One way to understand how bodily processes of movement and perception shape subjective experience in autism is to delve into the flourishing field of autism autobiography. Since the publication of David Eastham's Understand: Fifty memowriter poems (1985), autism narratives has become a steadily growing genre (Rose 2005; Bates 2010). Among many others, notable publications are Temple Grandin's Thinking in Pictures (2006), Donna Williams' Nobody nowhere (1992) and Liane Holliday Willey's Pretending to be normal: Living with Asperger's Syndrome (1999). In this article, I will focus on Tito Rajarshi Mukhopadhyay's How can I talk if my lips don't move (2011). A phenomenological analysis would ideally address several first-person accounts, but I have chosen to present an in-depth analysis of a single narrative in order to demonstrate the potential of phenomenology in understanding embodied subjectivity in autism.

Tito Mukhopadhyay was born in India in 1989 and was diagnosed with severe autism in early childhood. Although Tito has been practically non-verbal throughout his life, his mother Soma taught him to read and write at an early age. Shortly after BBC made the documentary Tito's Story (Terrill and Lichtenstein 2000), Tito and his mother were brought to the United States in 2001 on a sponsorship from Cure Autism Now (now merged with Autism Speaks). As will be discussed further below, there are several controversies surrounding Tito Mukhopadhyay and the Rapid Prompting Method, one of them being the issue of physical abuse. Mukhopadhyay himself describes how his mother was 'firm' with him as part of his training:

[S]he became my teacher. A very firm teacher who would not give me the next meal unless I used the pencil in the proper way. And because I was constantly 
dropping the pencil down she tied it to my hands with a rubber band. And when I was not completing the questions which she had given me after reading a chapter, I was tied down to the chair till I finished it. (Mukhopadhyay in Biklen et al. 2005:128)

Before going further into the phenomenological analysis of Mukhopadhyay's work, I want to state unequivocally that the use of Mukhopadhyay's descriptions in this article should not be regarded as an acknowledgement of the methods of Soma's training. I take Mukhopadhyay's work as a point of departure for the present analysis of embodied subjectivity in autism because his autobiographical account provides unique descriptions of autistic experience. At the heart of these descriptions, making them all the more interesting for the purpose of this article, lie issues centered on bodily self-experience, sensation, movement and perception. Besides describing problems that have long been recognized as fairly general for the autism spectrum, Mukhopadhyay expresses an aspect of these problems that is rarely known to non-autistic individuals. Namely, what meaning and sense are encountered in autistic symptoms from a first-person perspective.

As mentioned above, Tito has learned to write through the Rapid Prompting Method developed by his mother. Soma's method is similar to Facilitated Communication (FC) where communication by pointing, typing or writing is physically supported by a facilitator (Crossley 1992; Biklen 1990). In the Rapid Prompting Method, as the name suggests, communication relies on eliciting responses from the participant through the facilitator's use of physical, verbal, or auditory prompts. Critics of the Rapid Prompting Method and other forms of FC argue that these methods do not facilitate independent communication (Lang et al. 2014) and that the elicited responses from the participant are highly susceptible to facilitator influence (Schlosser et al. 2014). One could argue that this criticism provides ground for questioning the autonomy of Tito Mukhopadhyay's voice and the identification of his autobiography as a first-person account of autism. Notwithstanding, different forms of FC have also been celebrated in self-advocacy networks and the neurodiversity movement for providing opportunities for nonverbal individuals with autism to communicate "[...] ideas about their lives and their relationship to the world. "(Biklen et al. 2005:1). When reading the analysis of Mukhopadhyay's autobiographical account, I urge the reader to keep this controversy in mind and form his or her own opinion. However, there seems to be a danger looming in completely rejecting different forms of $\mathrm{FC}$ as a valid way of communicating in potentially discrediting the perspectives of individuals with severe autism.

Another caution when reading autistic autobiographies is voiced by Ian Hacking (2009). Mukhopadhyay's autobiographical work has by Portia Iversen been termed "a window into autism such as the world has never seen" (Iversen in Blakeslee 2002). This increasingly popular way of introducing autism narratives as a view 'inside the autistic mind' must, according to Hacking (2009), be regarded with some suspicion. Individuals with autism are as different from each other as 'neurotypical' people are. In other words, there is no 'the' autistic mind. For this reason, I will not argue that the points raised in the following analysis of Mukhopadhyay's work are 
representative of a general way of experiencing that can be termed autistic. Rather, Hacking (2009) is urging us to understand autistic narratives as creating new ways of describing the intentions, thoughts and feelings of autistic individuals underlying the (to people that are not autistic) sometimes rather baffling behavior. Although Hacking's point that autism narratives cannot be regarded as direct descriptions of what it is like to be autistic is important and convincing, I argue that it is nonetheless of paramount importance to develop a framework for understanding first-person experience in autism. I argue this, not only on the ground that autism research ought to take seriously the experience of autistic individuals, but also because developing structured approaches to subjective experience is essential in order to understand individuality and heterogeneity across the spectrum.

Mukhopadhyay's work has important value as the object of phenomenological analysis. Philosophical phenomenology has shown to be a fruitful frame of understanding in both psychology and psychopathology. This is most lately illustrated in schizophrenia research, where prominent psychiatrists and phenomenologists collaborate in the understanding of disturbances of pre-reflective selfexperience in the early stages of schizophrenia (Sass and Parnas 2003; Parnas et al. 2005). Regrettably, a comprehensive phenomenological account of autism has yet to be developed. The following analysis provides an example of how it is possible to engage phenomenological analyses with the field of autism research in order to understand the bodily and subjective experience of autistic individuals.

\section{Bodily Self-Experience and Self-Estrangement}

Bodily self-experience can be described, not as a conscious or explicit view of the body as if looking in a mirror, but as a tacit and pre-reflective awareness of one's own body accompanying any action, perception or thought. A central point in Merleau-Ponty's phenomenology is that the body does not primarily present itself to me as an object of experience. Although I can turn my attention toward my body and encounter it as if it were a constellation of individual parts, what really constitutes its being a body for me is its infatuation with subjectivity and life and the fact that it is always experienced as my own. In this way, the body cannot be understood as a complex constellation of parts; it presents itself rather as an undivided, although implicit, unity (Merleau-Ponty 2012:102). When I stretch myself to reach for a cup of coffee, I am not conscious of the complex interplay of movements between individual parts of my body necessary to perform this action. Rather, I direct the whole of my body toward a goal-retrieving the cup-being only implicitly aware of the fluency of the body's whole movement towards this goal.

During his childhood, Mukhopadhyay relied heavily on performing certain movements and actions in order to feel at ease with his body. In this case, he describes how he used the movements of the ceiling fan in his childhood home to maintain bodily feeling of ease and control: 
I would stand right below it, and rotate my body as fast as I could, wondering whether I too became as transparent as the fan. [...] I could gather my body parts while I rotated, so that I could feel my arms, legs, and fingers, in total control. [...] Once again, I felt sure of my movements and what I was supposed to see as I went around at that speed. Feeling sure calmed my senses. (Mukhopadhyay 2011:59-60)

The movements of the fan and the simultaneous movements of his own body seem to relieve him of a certain bodily feeling he describes encountering whenever the frequent power cuts stopped the fan from moving: "When there were power cuts, I felt helpless and scattered once again, as if my existence depended on the movements of the fan." (Mukhopadhyay 2011:63). 'Gathering' the parts of the body is ultimately what relieves Mukhopadhyay of this feeling of being scattered or disassembled. Gathering the parts of the body by spinning with the fan is understandable within the framework of Merleau-Ponty as a way to uphold a very basic sense of bodily self. Conversely, Mukhopadhyay's experience of being left with a fragmented body consisting of scattered parts points to a form of bodily selfestrangement. Experiencing the body as a bundle of disconnected parts is essentially an objectification where the body, rather than being an experiencing subject, is experienced as if it were an object in the physical world.

A more vivid description of self-estrangement that is closely related to the one described above can be found in Mukhopadhyay's memory of going to the doctor as a child. As discussed above, Mukhopadhyay's wellbeing was highly dependent on performing certain movements and actions, one being to climb up and down staircases.

I was puzzled. Mother had never stopped me from climbing any staircase before. [...] And when I got puzzled, I got disoriented. And when I got disoriented, I got scared. I felt as if my whole existence depended on those staircases. 'What if I stop existing when I stop climbing them?' Panic took over my eyes, blinding them shut. It took over my ears, deafening me with the sound of a scream, which was my own, as I recognized it. [...] My body and my surroundings were dissolved in the sound generated by my scream. Once it took control, I knew no one had any power to stop it. I had no power to stop it either. (Mukhopadhyay 2011:40-41)

What emerges here is a panic so intense that Mukhopadhyay loses touch with himself. To stop moving up and down the stairs means to stop existing, to lose the feeling of certainty and ease which the movement granted him. In his panic, he disconnects with himself in the sense that he loses the experience of ownership over his own body and is left with a scream that has become a mere auditory object, originating elsewhere and only recognized as his own as he hears the sound. 


\section{Movement and Motor Significance}

In the following excerpt, Mukhopadhyay describes how he is unable to execute the movements necessary to perform certain actions, in this case going to the adjourning room and retrieving his pen and notebook. As we shall see, his description reflects important aspects of bodily movement as understood by Merleau-Ponty.

My plan to write a few lines remained a mere plan because I could not get the mental map required to actually do anything beyond sitting where I was, or to implement my plan. My pencil and my notebook were in the next room, and I could not map my body to go and bring them, although I could very well visualize the process of opening a page and writing. (Mukhopadhyay 2011:126)

Viewed through the lens of Merleau-Ponty's phenomenology, what Mukhopadhyay is struggling with, is granting the thought of writing in his notebook an actual, bodily and motor significance. When Mukhopadhyay sees the pen in front of him, he can grab it without difficulty. But when the notebook is not positioned in the immediate vicinity, the object remains a mere thought severed from its concrete environment. Merleau-Ponty (2012:114) distinguishes between two aspects of movement: concrete movement as a practical handling of the world where the body adheres and responds to the immediate environment, and abstract movement that "sets up its own background." This latter aspect of movement consists in granting a bodily and motor signification to the world in which concrete movement unfolds. The world as it presents itself to us is not a mere constellation of physical objects positioned in space, but always already embedded with meaning and significations reflecting and inviting the projects and goals of the embodied subject. The subject is always directed toward the world, and conversely, the world is always inciting certain bodily attitudes, movements and actions. On this backdrop, Mukhopadhyay's difficulty with retrieving his pen and notebook can be understood as a difficulty with recognizing a bodily, motor significance to the desired objects. Consequently, they do not invite him to move his body in the required way; he cannot 'map' his body correctly.

Let us consider this notion of mapping, a term Mukhopadhyay uses repeatedly to describe his way of handling certain situations. He describes this process as "a mental picture I form, which I expect to face in the process of events [...]." (Mukhopadhyay 2011:191). Particularly necessary in stressful, confusing or otherwise overwhelming situations, mental maps function as ways of coping with the world by mapping out meticulously the position and movements of the body, the course of action and the corresponding position of the objects involved. In the following passage, Mukhopadhyay describes the role of mental maps when acquiring new practical skills, in this case, buttoning a shirt:

To button my shirt, I used only one hand at first. I could not use two hands in two different ways. Buttoning needs two hands working in two different ways, each hand supporting the other in a cooperative effort. [...] Once I understood the task, I could map it well around my body. Every successive try got this 
kind of mapping well established in my mind. [...] And I began to map out the buttons, not just like a visually impaired person, as I previously did. (Mukhopadhyay 2011:74-75)

The way Mukhopadhyay gradually maps out the relation between his two hands working together, the shirt, its sleeves and buttons is a form of awareness of the body in relation to the object of its activity. For Merleau-Ponty, bodily selfawareness is not a mere mental picture of the body isolated from its current environment and task, but rather a pre-reflective experience of the body as engaged in the world at hand. When the body immerses itself in the world, it involves a tacit self-awareness that may best be described in terms of a familiarity or intuitive feel of the movements of the body as it engages in a certain task. Mukhopadhyay's description of learning how to button his shirt indicates in its own way a break with this bodily familiarity with the world. It is worth bringing forth Merleau-Ponty's own description of the type of bodily understanding involved in our practical engagement with the world:

It is a question of a knowledge in our hands, which is only given through a bodily effort and cannot be translated by an objective designation. The subject knows where the letters are on the keyboard just as we know where one of our limbs is - a knowledge of familiarity that does not provide us with a position in objective space. (Merleau-Ponty 2012:145)

According to Merleau-Ponty, this intimate relationship between body and world cannot be captured by reference to conceptual or reflective knowledge. Yet, Mukhopadhyay's mental mapping, a highly reflective activity, seems to be exactly what establishes the crucial connection between body and world. Merleau-Ponty argues that the reflective, mental activity, that Mukhopadhyay relies on in order to act, is presupposed by a pre-reflective awareness of the body in its engagement with its surroundings. It seems reasonable to consider whether Mukhopadhyay's dependence on mental maps is a way of coping with a diminished pre-reflective bodily self-awareness. Mukhopadhyay's difficulty with making his two hands work together (as though initially disconnected from each other) bears a certain likeness to his description of gathering his body parts under the spinning fan. It seems as though these situations might share a common core, namely the feeling of detachment from one's own body as a silent background for action.

\section{Sensory Experience}

In the following section, we will look at the body as a sensory being, more precisely at the experience of the body sensing the world and the experience of the body sensing itself. Mukhopadhyay describes how his tactile hypersensitivity affects the process of learning how to write:

[...] due to my selective tactile defenses, holding a new object was a real pain. [...] My senses were strained by practicing holding the pencil, resulting in discomfort, the kind you feel when the hair of your legs are stroked in opposite 
direction of their growth. It was like wearing a new pair of shoes. (Mukhopadhyay 2011:158-159)

Holding the pencil overstimulates Mukhopadhyay's tactile sense to such a degree that it becomes impossible for him to hold on it. He compares the sensation to wearing a new pair of shoes:

New shoes made my feet look detached from the rest of me. My senses got so strained that I refused to lay my feet on the ground. [...] And I remember it through the intensity of that experience, which accumulated my senses, all at once, merging together with banging stress. (Mukhopadhyay 2011:85)

Notably, Mukhopadhyay's memory of the tactile experience of the new shoes relates to a feeling of the feet as detached from the rest of the body. When overstimulated by the new leather shoes, the feet announce themselves as objects of awareness. Merleau-Ponty (2012:103) describes bodily space as "the darkness needed in the theater required for the clarity of the performance" and "the zone of non-being in front of which precise being, figures, and points can appear." In other words, when we experience the world the body is the experiential null-point, from which we experience, and not an object of experience itself. In the situation described by Mukhopadhyay, the feet demand his attention to them as objects of experience and refuse to reside into the anonymity of the body as the background of experience.

On one hand, Mukhopadhyay's sense experience reveals the body as an object of attention rather than being identical with himself as a subject living and acting in the world. On the other hand, we find in Mukhopadhyay's descriptions a body that has vanished from the field of experience, emphasizing instead a radically diminished bodily self-awareness:

To learn the sensation of physical pain, I had to mentally experience it. My mind needed to judge the location of the pain, the structure of the pain, and the nature of the pain. Mother had to guess what caused my screams. [...] Mother began to teach me. She closed my eyes and tapped different parts of my arms and legs. She asked me to point to the body part that she had tapped. [...] Was any pain involved in those taps, scratches, or rubs? I do not know because I missed those spots initially. (Mukhopadhyay 2011:209-210)

The body, being one's own body, means that sensation is felt, not coming from some place or object, but being inextricable from the body itself (Merleau-Ponty 2012:96). When I experience a pain, I simultaneously experience a familiarity with my own body as a first-person perspective: as the subject of experience encountering the pain. In the situation described by Mukhopadhyay, he does not intuitively experience where the pain is felt and is once again left with a mental analysis of the problem, learning step by step how to judge and analyze the location and nature of the pain. The heart of the ambiguity then, is this: In some cases, Mukhopadhyay experiences his body in a radically intensified manner, and in other cases, his body as the locus of sensitivity seems to be altogether disappearing from his field of experience. 
So far we have discussed sensation as a type of bodily self-experience, focusing primarily on how the body presents itself as a sensing subject. However, Mukhopadhyay also describes sense experience in a broader sense, namely as delivering a fundamentally chaotic, unpredictable and overwhelming world. In the following passage, Mukhopadhyay describes how playing a game of badminton constitutes what he terms an 'unpredictable situation' and his bodily reaction when he can no longer focus on the game:

It's like a total shutdown of the senses. It is as though the eyes stop seeing and the ears stop listening. What do I do then? I usually flap my hands to distract my senses to a kinesthetic feel, so that my senses may be recharged. [...] If that failed, I would seek out a more predictable situation where my senses would reconnect in a more meaningful way, so that I could connect my body once again with the environment. (Mukhopadhyay 2011:140)

When Mukhopadhyay is no longer able to focus his attention on all the simultaneously occurring aspects of the game (the movement of the shuttlecock and of his own body, the perceptual surroundings, the position of the opponent etc.), his senses 'shatter', making both physical and mental activity impossible to continue. An interesting theme in this passage is that Mukhopadhyay manages to handle this situation by 'recharging' his senses through flapping his hands. The movement is described as a distraction, where his senses, instead of being burdened with the chaotic perceptual environment, turn toward the sensation of his own body in motion: toward a sense of bodily self. In this way, hand flapping is a way of restoring a connection to oneself that ultimately restores the relation between the body and its environment.

Taken together, hand flapping and the previously discussed mental maps represent two ways of dealing with an overwhelming world: a mental one, where all aspects of a situation is mapped out to predict the outcome of events and actions, and a bodily one that returns the Mukhopadhyay to a feeling of oneself as a motor subject. What world is it that needs to be made predictable, safe and familiar through these basic strategies? Let us turn our attention more directly to how Mukhopadhyay describes his perceptual experience.

\section{Perceptual Experience}

How do objects come to be for us? How do they come to present themselves as parts of a world infatuated with meaning? These are some of the most crucial questions for Merleau-Ponty in Phenomenology of Perception, and they present themselves in a more concrete sense in the following description by Mukhopadhyay, where he encounters an unfamiliar object:

The first thing I see is its color. If I do not get into a deeper cogitation of its color by defining it as 'yellow,' and mentally lining up all the yellow things I know of, including one of my yellow tennis balls when I was seven years old, I move to the shape of the door. And if at all I lay my eyes on the door hinge, I 
might get distracted by the functions of levers. However, I pull my attention from there and wonder about the function of that yellow, large rectangular object, with levers of the first order, called a hinge. Why is that yellow, large rectangular object with levers there? I mentally answer the question, 'It has allowed me to come inside that room, and can be opened or closed. And what else can that be, other than a door.' My labeling is complete. (Mukhopadhyay 2011:95)

What Mukhopadhyay alludes to here is when and how the object in front of him ceases to be a collection of independent parts and details and suddenly present themselves as a door. This happens through an effortful mental analysis of the individual details of the door in order to finally arriving at a conclusive identification. Merleau-Ponty describes perception as a spontaneous process, where the individual details only appear through the whole of the object rather than constituting it. Merleau-Ponty (2012:294) emphasizes how we, in fact, "[...] hardly perceive any objects at all, just as we do not see the eyes of a familiar face, but rather its gaze and its expression." Stated differently, we do not normally perceive the objective character of the things in front of us, but rather their meaning and core. On this backdrop, Mukhopadhyay's perception appears like a fragmented encounter of a jumble of disintegrated details and parts, where he struggles through the process of gathering the individual properties, struggles to make sense of it as a door. The meaning of the object does not arrive to Mukhopadhyay intuitively and spontaneously, as Merleau-Ponty emphasizes, but through a laborious process of mental labelling.

It becomes increasingly apparent how Mukhopadhyay's immersion in isolated features of the perceptual environment substitutes the intuitive grasp of the whole of the object or situation. Merleau-Ponty (2012:294) describes that perception of an object always takes place on the background of a perceptual field that animates the object with a certain sense. The perceptual field_or milieu —is not something one is consciously aware of, but is nonetheless an implicit and taken for granted background of meaning upon which the perception in question stands out. When perceiving an object, we have a pre-reflective grasp on its meaning. It is this feature of perceptual experience that Mukhopadhyay seems to be struggling with, substituting it instead with a reflective and analytic attitude toward the object of his experience.

Going back to the discussion of bodily self-experience, it is worth devoting some attention to Merleau-Ponty's (2012:212) point that "[e]very external perception is immediately synonymous with a certain perception of my body, just as every perception of my body is made explicit in the language of external perception." Following this point, I want to suggest a continuity between Mukhopadhyay's bodily self-experience and the way he describes his perceptual experience as discussed above. It was discussed how the pre-reflective bodily self-experience was substituted with an explicit and reflective awareness of the body as an accumulation of independent parts. This form of experience, in which a reflective and conscious attitude is directed towards something normally taken-for-granted and only implicitly present, was discussed also as a trait of Mukhopadhyay's perceptual 
experience. The door did not spontaneously present itself as embedded with 'doorness,' but only made sense after an effortful analytic process. Furthermore, the same shift in balance between pre-reflective and reflective awareness announced itself in Mukhopadhyay's need to map out himself and his surroundings when performing certain actions or learning new practical skills.

According to Merleau-Ponty, the world makes sense to us intuitively and immediately by virtue of the body being a lived unity projecting itself towards its environment and grasping it as a field of possibilities. In this way, the body forms a system with the world (Merleau-Ponty 2012:209) that essentially presents itself as a relation of intimacy on the ground of which things intuitively appear meaningful as parts of a familiar environment, much like the way one's home presents itself in everyday experience. When walking through my home, I do not need to think about the location of my arm in relation to the location of the door-handle. I do not need to plan a series of movements in order to reach for the milk in the fridge, just like I don't need to be careful not to bump into that table whose corner is always in the way. This example gives a concrete sense to Merleau-Ponty's point that we inhabit the world. This feeling of being at home, of taken-for-granted-ness or of merely being present in the world seems to be fragile in Mukhopadhyay's experience and instead characterized by a feeling of uncertainty.

In Merleau-Ponty's phenomenology, bodily self-experience and perception of the world are closely interwoven with the movements of the body and the implicit feeling of one's own bodily agency. Our bodily movements continuously shape the perceptual field and the possibility of interacting with the environment constitutes a crucial part of how the world presents itself as meaningful in our experience. The movements of the body are an essential part of establishing the intimate relation with the world that makes it appear intuitively meaningful. For Mukhopadhyay, bodily movement is ultimately what ends up establishing a bodily connection with himself and with the world. Spinning beneath the ceiling fan granted a feeling of certainty and bodily self, just like climbing up and down the staircases secured a stable sense of his own bodily being. Finally, flapping his hands in a stressful situation returned his senses to his own body as the initiator of the movement; a basic bodily self-awareness making the perceptual environment more manageable. In this way, Mukhopadhyay's story articulates a fragile relationship between subject, body and world, and furthermore, how it is possible to momentarily restore it through bodily movement.

\section{Discussion}

In order to arrive at a proper sense of what distinguishes a phenomenological account centered on embodied subjectivity from other approaches to autism, we need to return to the two approaches introduced in the beginning of this paper; namely the dominant cognitive paradigm of theory of mind research and the growing body of research in sensorimotor differences in autism. Beginning with the former, theory of mind research is based on the idea that social understanding requires the application of mental state concepts by way of higher-order cognitive 
abilities. The gradual maturation of the cognitive system thus marks the evolving ability to comprehend more and more complex mental states and, based on observed behavior, apply them successfully to others (Baron-Cohen 1995:31). The theory of mind deficit approach to autism is based on a rapidly growing field of empirical research demonstrating how autistic children are significantly less able to perform the reasoning processes involved in correctly ascribing complex mental states to other people. Accordingly, theory of mind construes autism as a local impairment in the cognitive system responsible for understanding the perspectives of others. In the words of prominent autism researcher, Simon Baron-Cohen (1995), autistic children are mindblind.

In recent years, a significant amount of criticism has been directed toward theory of mind research, both as a theoretical account of social understanding and as a theory of autism. Ivan Leudar and Alan Costall (2009:10) emphasize that the theory of mind paradigm in cognitive psychology invokes the basic assumptions of psychological behaviorism by instituting a split between observable, physical behavior as opposed to private, unobservable mental states. This point is substantiated from within the field sensorimotor research, where Maria Brincker and Elizabeth Torres (2013) point out that within the cognitive paradigm of autism, cognitive abilities are construed as disembodied functions. Further, Caroline Whyatt and Cathy Craig (2013) emphasize how cognitively driven theories of autism fail to take into account the rich variety of bodily problems in autism related to movement and perception.

As previously discussed, two major ambitions emerge from the sensorimotor perspective on autism: (1) developing ways to objectively measure and quantify human behavior and (2) to ground the scientific view of autism in the experience and perspectives of autistic individuals. As suggested earlier, these two ambitions are hard to reconcile. Mainly because, as we have seen, the body as it presents itself in subjective experience cannot be measured objectively-in this way a gap emerges between the scientific account of autism and the subjective experience of autistic individuals. If we truly want to understand subjective experience of sensorimotor problems in autism, we must adopt a different view on the body than one grounded in a naturalistic frame of understanding. We must understand the body as the basis of subjective experience rather than as an object whose properties are available for measurement and quantification.

This is what I have demonstrated in the analysis of Mukhopadhyay's first-person account. I have approached an understanding of embodied subjectivity in autism by showing how phenomena that we would classify as of a mental or psychological nature are grounded in bodily being, and conversely, that phenomena normally regarded as of a physical nature are embedded with a subjective sense. For instance, the ways in which Mukhopadhyay moved his body (up and down the stairs, spinning below the ceiling fan, or flapping his hands) should not be understood as purely physical acts. Rather, they presented themselves with an intrinsically subjective meaning as explications of a certain bodily self-experience and as ways to reinstate a relation between body-subject and world. Furthermore, I have shown how mental or cognitive phenomena (the development of mental maps or the integration of sensory input) was infatuated with a bodily and motor sense. Following an 
important point in sensorimotor research on autism, I emphasized autistic movement as more than an expression of cognitive or social impairment. Autistic movement and behavior should be considered meaningful and sensible as ways of understanding, responding and relating to the environment and oneself as an experiencing subject. This way of understanding movement and behavior points to a notion of the body as the locus of subjectivity, and of bodily subjectivity as an activity in which the body-subject projects itself into the world.

A number of themes have emerged in the analysis of Mukhopadhyay's work that resonate well with experiences recounted in a number of different autobiographical accounts and first-person descriptions of autism. Differences in bodily selfexperience are described in Grandin (2006), Williams (1992), Rajapatirama (in Wallis 2006) and qualitative studies of sensory and motor differences (Robledo, Donnellan, and Strandt-Conroy 2012). The autistic writer and poet Chandima Rajapatirama further describes the relation between a basic sense of bodily self and the ability to perform everyday actions which also feature prominently in Mukhopadhyay's account and is further described by Sue Rubin (Rubin et al. 2001) and Alberto Frugone (Biklen et al. 2005). As is also described in many accounts by autistic individuals (see for example Nazeer 2006, Blackburn 2000 and Davidson 2010), Mukhopadhyay uses self-stimulatory movement is a way of tackling an overwhelming, unpredictable and chaotic world. ${ }^{2}$ Another strategy for Mukhopadhyay is the effortful cognitive analysis of situations, which he terms 'mapping.' As shown in Emma Williams' analysis (2004), a common theme in autistic autobiography is taking a reflective and analytical attitude toward situations that by non-autistics are usually handled intuitively and without cognitive effort. Williams addresses the way autistic individuals handle the unpredictability and complexity of social situations. This draws attention to an aspect of autistic experience that does not figure very prominently in Mukhopadhyay's account: how sensorimotor differences may affect the experience of and engagement in social situations. As described by Charles Hale, movement difficulties may cause challenges with bodily expression in social situations:

[W]hen I should be smiling, sometimes I know that I am not smiling but may be even frowning. This causes me a great deal of pain and makes me look as though I am not comprehending when, in fact, I am crying to respond in an appropriate manner. (Hale and Hale 1999:32)

This calls for further exploration of how a different way of experiencing the world and oneself might affect how autistic individuals engage in social situations and interactions. Damian Milton (2012, 2014b) emphasizes how differences between autistic experience and non-autistic experience of sociality causes a breach in the reciprocity and mutuality of social interaction. This creates a 'double empathy

\footnotetext{
${ }^{2}$ Research has traditionally depicted repetitive, stereotyped or self-stimulatory behaviors in autism from a behaviorist perspective as something to be eliminated or treated (Boyd, McDonough, and Bodfish 2012). However, recent research emphasizes the productive and positive value of these behaviors as ways of managing a chaotic and overwhelming environment (Sinha et al. 2014; Davidson 2010), as sources of pleasure, social engagement between autistics or even as cultural and artistic expression (Bakan 2014; Nolan and McBride 2015; Conn 2015).
} 
problem' that is irreducible to potential impairments or cognitive deficits on the part of the autistic person. Milton argues that social situations are jointly negotiated and constructed, and cannot be 'psychologized' in the way that the dominant cognitive paradigm in autism research would have it. Milton and other autistic academics and self-advocates object to the view that autism is a "dysfunctional deviation from an idealized notion of normalcy" (Milton 2014b:6), and to the fact that autistic voices and experiences are often neglected in mainstream autism research:

Such views are informed by research that [...] discounts the subjective experiences of those who identify as being on the autism spectrum themselves as worthy of rigorous academic study. (Milton 2012:884)

Including autistic people in research and knowledge production as both researchers and co-researchers is a promising beginning toward balancing the distribution of power in autism research. As I have argued earlier in this article, including the experiences of autistic individuals as a basis for knowledge claims about autism requires a framework within which to understand and conceptualize such experience. In other words, if we are to use autistic experience as a basis for understanding autism, we need to get serious about studying experience systematically and rigorously.

What phenomenology offers in this context is a conceptual and methodological framework that studies subjective experience and embodiment in a number of different areas highly relevant to autism research, such as perception, movement and sociality. As a frame of understanding in psychology, phenomenology calls for an approach to subjectivity solidly grounded in empirical investigations of first-person experience through rigorous analysis of experiential descriptions obtained through qualitative methodology. Reiterating Husserl's demand that phenomenology should remain descriptive, phenomenological psychology is aimed at staying as close to concrete experience as possible while trying to describe the meaning with which phenomena present themselves to the experiencing subject (Giorgi 2009:98). In his description of what characterizes phenomenology as a method, Daniel Schmicking (2010:41) stresses that this notion of describing phenomena as they appear in experience is not so straightforward and simple as it may seem. Phenomenologists are interested in the ways in which phenomena present themselves, and this is exactly what poses the challenge, because the ways in which we experience are not what makes up the content of the experience. Phenomenology explores the structures that shape concrete experience, rather than what the experience is about. In this way, the ambition in phenomenological psychology is to approach the experiential structures presupposed by our reflective awareness of the world.

Focusing on the structures of experience made it possible to sketch out certain continuities between the experiences described by Mukhopadhyay that might not otherwise be easy to spot. For instance, a basic sense of uncertainty or loss of a prereflective grasp of his own body and surroundings permeated a manifold of different experiential situations. This pointed to a break in the relationship between himself as an embodied subject and the world as a meaningful field for possible action. Moreover, it was possible to understand different strategies to secure and anchor this relationship between body-subject and world: a mental variant where 
Mukhopadhyay reflectively tries to make the world sensible and predictable, and a bodily one functioning as a way of stabilizing the experience of an acting, bodily self.

\section{Conclusion}

In this paper, I have demonstrated the relevance and potential of understanding firstperson experience in autism through the phenomenological notion of embodied subjectivity. Developing a systematic framework for understanding subjective experience in autism is of immense importance for several reasons. First, it allows us ground the scientific understanding of autism in the experience of autistic individuals, thereby avoiding theoretically driven misconceptions about autistic behavior. Secondly, an understanding of embodied subjectivity bridges the gap between physical and mental phenomena and shows how these apparent dualities are interwoven and inseparable aspects of being human. Adopting a phenomenological frame of understanding requires an openness toward exploratory and qualitatively driven research models, which stand in contrast to experimental research paradigms where a hypothesis can be tested without exploring the subjective experience of the research participants. Furthermore, it requires a willingness to work with sometimes rather equivocal philosophical analyses and notions that are hard to operationalize. I believe, however, that the meaning of subjective experience is exactly to be found in that complexity, and that it is worth the effort in order to begin grounding scientific knowledge about autism in the experiences of autistic individuals themselves.

\section{Compliance with Ethical Standards}

Conflict of interest The author states that there is no conflict of interest.

\section{References}

Arnold, Laurence

2012 Autism, Its Relationship to Science and to People with the Condition. Autonomy, the Critical Journal of Interdisciplinary Autism Studies 1(1). http://www.larryarnold.net/Autonomy/index. php/autonomy/article/view/AR2.

Bakan, Michael B.

2014 The Musicality of Stimming: Promoting Neurodiversity in the Ethnomusicology of Autism. MUSICultures 41(2):133-161.

Baron-Cohen, Simon

1995 Mindblindness. An Essay on Autism and Theory of Mind Cambridge, Massachusetts: The MIT Press.

Baron-Cohen, Simon, Alan M. Leslie, and Uta Frith

1985 Does the Autistic Child Have a 'Theory of Mind'?. Cognition 21:37-46.

Bates, Gordon

2010 Autism in Fiction and Autobiography. Advances in Psychiatric Treatment 16:47-52.

Biklen, Douglas

1990 Communication Unbound: Autism and Praxis. Harvard Educational Review 60:291-314. 
Biklen, Douglas, Richard Attfield, Larry Bissonnette, Lucy Blackman, Jamie Burke, Alberto Frugone,

Tito Rajarshi Mukhopadhyay, and Sue Rubin

2005 Autism and the Myth of the Person Alone. New York, NY: NYU Press.

Blackburn, Ros

2000 Within and Without Autism. Good Autism Practice 1(1):2-8.

Blakeslee, Sandra

2002 A Boy, a Mother And a Rare Map Of Autism's World.” The New York Times. 2002. http://www. nytimes.com/2002/11/19/science/a-boy-a-mother-and-a-rare-map-of-autism-s-world.html.

Boldsen, Sofie

2016 A Phenomenology of the Autistic Body. The Relevance and Potential of Merleau-Ponty's Phenomenology as Frame of Understanding in Autism Research. Roskilde University.

Boyd, Brian A., Stephen G. McDonough, and James W. Bodfish

2012 Evidence-Based Behavioral Interventions for Repetitive Behaviors in Autism. Journal of Autism and Developmental Disorders 42(6):1236-1248.

Brincker, Maria, and Elizabeth B. Torres

2013 Noise from the Periphery in Autism. Frontiers in Integrative Neuroscience 7:34.

Conn, Carmel

2015 'Sensory Highs', 'Vivid Rememberings' and 'Interactive Stimming': Children's Play Cultures and Experiences of Friendship in Autistic Autobiographies. Disability \& Society 30(8):11921206.

Crossley, Rosemary

1992 Getting the Words Out II: Case Studies in Facilitated Communication Training. Topics in Language Disorders 12(4):46-59.

Dant, Tim

2015 In Two Minds: Theory of Mind, Intersubjectivity, and Autism. Theory \& Psychology 25(1):4562.

Davidson, Joyce

2010 'It Cuts Both Ways': A Relational Approach to Access and Accommodation for Autism. Social Science \& Medicine 70(2):305-312.

De Jaegher, Hanne

2013 Embodiment and Sense-Making in Autism. Frontiers in Integrative Neuroscience 7:15.

Donnellan, Anne M., David A. Hill, and Martha R. Leary

2012 Rethinking Autism: Implications of Sensory and Movement Differences for Understanding and Support. Frontiers in Integrative Neuroscience 6:124.

Eastham, David

1985 Understand: Fifty Memowriter Poems. Ottawa: Oliver Pate.

Giorgi, Amedeo

2009 The Descriptive Phenomenological Method in Psychology: A Modified Husserlian Approach. Pittsburgh, Pennsylvania: Duquesne University Press.

Glenberg, Arthur M., Jessica K. Witt, and Janet Metcalfe

2013 From the Revolution to Embodiment: 25 Years of Cognitive Psychology. Perspectives on Psychological Science 8(5):573-585.

Graby, Steve

2012 To Be or Not to Be Disabled: Autism, Disablement and Identity Politics. Presented at the "Theorizing Normalcy and the Mundane" Conference, University of Chester, Chester, 27th of June.

Grandin, Temple

2006 Thinking in Pictures: And Other Reports from My Life with Autism. London: Bloomsbury Publishing Plc.

Hacking, I.

2009 Autistic Autobiography. Philosophical Transactions of the Royal Society B: Biological Sciences 364:1467-1473.

Hale, Mary Jane Gray, and Charles Martel Hale

1999 I Had No Means to Shout! Bloomington, IN: 1st Books.

$\mathrm{He}$, Jing, and Ejgil Jespersen

2015 The Embodied Nature of Autistic Learning: Implications for Physical Education. Physical Culture and Sport. Studies and Research 65(1):63-73. 
Huws, Jaci C., and Robert S.P. Jones

2015 'I'm Really Glad This Is Developmental': Autism and Social Comparisons-An Interpretative Phenomenological Analysis. Autism 19:84-90.

Kapp, Steven K.

2013 Empathizing with Sensory and Movement Differences: Moving toward Sensitive Understanding of Autism. Frontiers in Integrative Neuroscience 7:38.

Kristensen, Stefan

2012 The Noisy World of the Flesh. Autism, the Feldenkrais Method and Merleau-Ponty's Ontology. Presented September 20th at the 37th Annual Meeting: International Merleau-Ponty Circle, Fordham University, New York.

Lang, Russell, Amy Harbison Tostanoski, Jason Travers, and James Todd

2014 The Only Study Investigating the Rapid Prompting Method Has Serious Methodological Flaws but Data Suggest the Most Likely Outcome Is Prompt Dependency. Evidence-Based Communication Assessment and Intervention 8(1):40-48.

Leary, Martha R., and David A. Hill

1996 Moving on: Autism and Movement Disturbance. Mental Retardation 34:39-53.

Leudar, Ivan, and Alan Costall

2009 Introduction: Against 'Theory of Mind'. In Against Theory of Mind. Ivan Leudar and Alan Costall, eds., pp. 1-16. London: Palgrave Macmillan UK.

Merleau-Ponty, Maurice

2012 Phenomenology of Perception. Translated by Donald A. Landes. Oxon-New York: Routledge.

Milton, Damian

2012 On the Ontological Status of Autism: The 'Double Empathy Problem'. Disability \& Society 27(6):883-887.

2014a Becoming Autistic: An Aut-Ethnography. Cutting Edge Psychiatry in Practice 4: 185-92.

2014b Embodied Sociality and the Conditioned Relativism of Dispositional Diversity. Autonomy, the Critical Journal of Interdisciplinary Autism Studies 1(3). http://www.larryarnold.net/Autonomy/ index.php/autonomy/article/view/32.

Milton, Damian, Richard Mills, and Elizabeth Pellicano

2012 Ethics and Autism: Where Is the Autistic Voice? Commentary on Post et al. Journal of Autism and Developmental Disorders 44(10):2650-2651.

Milton, Damian, and Lyte Moon

2012 'And That, Damian, Is What I Call Life-Changing': Findings from an Action Research Project Involving Autistic Adults in an Online Sociology Study Group. Good Autism Practice 13(2):3239.

Mukhopadhyay, Tito Rajarshi

2011 How Can I Talk If My Lips Don't Move: Inside My Autistic Mind. New York, NY: Arcade Publishing.

Murray, Dinah, Mike Lesser, and Wendy Lawson

2005 Attention, Monotropism and the Diagnostic Criteria for Autism. Autism 9(2):139-156.

Nazeer, Kamran

2006 Send in the Idiots: Stories from the Other Side of Autism. London: Bloomsbury Publishing Plc.

Newman, Claire, Andrew Cashin, and Cheryl D. Waters

2010 A Modified Hermeneutic Phenomenological Approach toward Individuals Who Have Autism. Research in Nursing and Health 33(3):265-271.

Nolan, Jason, and Melanie McBride

2015 Embodied Semiosis: Autistic 'Stimming' as Sensory Praxis. In International Handbook of Semiotics. Peter Pericles Trifonas, ed., pp. 1069-1078. Dordrecht: Springer.

Parnas, Josef, Paul Møller, Tilo Kircher, Jørgen Thalbitzer, Lennart Jansson, Peter Handest, and Dan Zahavi

2005 EASE: Examination of Anomalous Self-Experience. Psychopathology 38(5):236-258.

Pellicano, Elizabeth, Adam Dinsmore, and Tony Charman

2013 A Future Made Together: Shaping Autism Research in the UK. London.

Rasmussen, Torben Hangaard

unpublished The Lived World of the Autist: A Phenomenological Approach. The Society For Existential Phenomenology 1-18. http://www.livsverden.dk. 
Robledo, Jodi, Anne M. Donnellan, and Karen Strandt-Conroy

2012 An Exploration of Sensory and Movement Differences from the Perspective of Individuals with Autism. Frontiers in Integrative Neuroscience 6:107.

Rose, Irene

2005 Autistic Autobiography_-Introducing the Field. In Proceedings of the Autism and Representation: Writing, Cognition, Disability Conference.

Rubin, S., D. Biklen, C. Kasa-Hendrickson, P Kluth, D.N. Cardinal, and A. Broderick

2001 Independence, Participation, and the Meaning of Intellectual Ability. Disability and Society 16(3):415-429.

Sass, Louis A., and Josef Parnas

2003 Schizophrenia, Consciousness, and the Self. Schizophrenia Bulletin 29(3):427-444.

Schlosser, Ralf W., Susan Balandin, Bronwyn Hemsley, Teresa Iacono, Paul Probst, and Stephen von

Tetzchner

2014 Facilitated Communication and Authorship: A Systematic Review. Augmentative and Alternative Communication 30(4):359-368.

Schmicking, Daniel

2010 A Toolbox of Phenomenological Methods. In Handbook of Phenomenology and Cognitive Science. Daniel Schmicking and Shaun Gallagher, eds., pp. 35-55. Dordrecht: Springer.

Sinha, Pawan, Margaret M. Kjelgaard, Tapan K. Gandhi, Kleovoulos Tsourides, Annie L. Cardinaux, Dimitrios Pantazis, Sidney P. Diamond, and Richard M. Held

2014 Autism as a Disorder of Prediction. Proceedings of the National Academy of Sciences 111(42):15220-15225.

Stawarska, Beata

2006 Mutual Gaze and Social Cognition. Phenomenology and the Cognitive Sciences 5(1):17-30.

Terrill, Christopher (Producer), and Olivia Lichtenstein (Editor)

2000 Tito's Story. England: BBC One London.

Torres, Elizabeth B., and Anne M. Donnellan

2015 Editorial for Research Topic 'Autism: The Movement Perspective'. Frontiers in Integrative Neuroscience 9:12.

Wallis, Claudia

2006 Inside the Autistic Mind. Time-New York-American Edition, 2006. http://content.time.com/ time/magazine/article/0,9171,1191843,00.html.

Whyatt, Caroline, and Cathy Craig

2013 Sensory-Motor Problems in Autism. Frontiers in Integrative Neuroscience 7:51.

Willey, Liane Holliday

1999 Pretending to Be Normal: Living with Asperger's Syndrome (Autism Spectrum Disorder). London: Jessica Kingsley Publishers.

Williams, Donna

1992 Nobody Nowhere: The Remarkable Autobiography of an Autistic Girl. London: Doubleday.

Williams, Emma

2004 Who Really Needs a 'Theory' of Mind?: An Interpretative Phenomenological Analysis of the Autobiographical Writings of Ten High-Functioning Individuals with an Autism Spectrum

Zahavi, Dan Disorder. Theory \& Psychology 14(5):704-724.

2005 Subjectiviy and Selfhood-Investigating the First Person Perspective. Cambridge, Massachusetts: The MIT Press.

Zahavi, Dan, and Josef Parnas

2003 Conceptual Problems in Infantile Autism Research: Why Cognitive Science Needs Phenomenology. Journal of Conciousness Studies 10(9-10):53-71.

Zukauskas, Patricia Ribeiro, Nava Silton, and Francisco Baptista Assumpção

2009 Temporality and Asperger's Syndrome. Journal of Phenomenological Psychology 40:85-106. 